\title{
The association between treated psychiatric and neurodevelopmental disorders and out-of-home care among Finnish children born in 1997
}

\author{
Antti Kääriäläl,2,3 $\cdot$ David Gyllenberg ${ }^{1,3,4} \cdot$ Reijo Sund $^{5} \cdot$ Elina Pekkarinen $^{6} \cdot$ Markus Keski-Säntti $^{7} \cdot$ Tiina Ristikari $^{7,8}$. \\ Tarja Heino ${ }^{1} \cdot$ Andre Sourander ${ }^{3,9}$
}

Received: 5 February 2021 / Accepted: 31 May 2021 / Published online: 8 June 2021

(c) The Author(s) 2021

\begin{abstract}
Comprehensive overviews of the use of psychiatric services among children and adolescents placed in out-of-home care (OHC) by child welfare authorities are scarce. We examine specialized service use for psychiatric and neurodevelopmental disorders among children and adolescents in a total population involving children in OHC. We used the longitudinal administrative data of a complete Finnish birth cohort $1997(N=57,174)$. We estimated risk ratios $(R R \mathrm{~s})$ for a range of diagnosed psychiatric and neurodevelopmental disorders among children in OHC. We also estimated RRs for OHC among those with diagnosed disorders. We used descriptive methods to explore the timing of first entry into OHC relative to the first diagnosis. Among children in OHC, 61.9\% were diagnosed with any psychiatric or neurodevelopmental disorder, compared with $18.0 \%$ among those never in $\mathrm{OHC}(R R: 3.7 ; 95 \% \mathrm{CI} 3.6-3.8)$. The most common diagnosed disorders among children in OHC were depression and anxiety disorders, neurodevelopmental disorders, and oppositional defiant disorder/conduct disorder (ODD/ $\mathrm{CD}$ ). Among all children with any diagnosis, $18.1 \%$ experienced OHC, compared with $2.5 \%$ among those without a diagnosis (RR: 7.4; 95\% CI 6.9-7.9). Of those diagnosed with self-harm and suicidality, ODD/CD, substance-related disorders, and psychotic and bipolar disorders, 43.5-61.2\% experienced OHC. Of the children in OHC receiving psychiatric services, half were diagnosed before first placement in $\mathrm{OHC}$. The majority of children with experience in $\mathrm{OHC}$ were diagnosed with psychiatric or neurodevelopmental disorders. They comprised a significant proportion of individuals treated for severe and complex psychiatric disorders and self-harm.
\end{abstract}

Keywords Psychiatric disorders $\cdot$ Neurodevelopmental disorders $\cdot$ Self-harm $\cdot$ Child welfare $\cdot$ Out-of-home care

\section{Introduction}

According to a global estimate, approximately 2.7 million children live in out-of-home care (OHC) due to their need for child welfare [1], which aims at securing children's health and development in the presence of adverse circumstances. Children placed in $\mathrm{OHC}$ are known to have high

Antti Kääriälä

antti.kaariala@thl.fi

1 Finnish Institute for Health and Welfare (THL), Helsinki, Finland

2 Faculty of Social Sciences, University of Helsinki, Helsinki, Finland

3 Research Centre for Child Psychiatry and INVEST Research Flagship, University of Turku, Turku, Finland

4 Department of Adolescent Psychiatry, Helsinki University Hospital, Helsinki, Finland need and expenditure for, and high use of, mental health services [2-16], with several studies highlighting the importance of timely provision of evidence-based interventions $[10,17,18]$. To facilitate the service planning of psychiatric services for children in $\mathrm{OHC}$ and child welfare services for children in psychiatric care, it is essential to have overarching knowledge of the concomitant use of these two services,

5 Institute of Clinical Medicine, University of Eastern Finland, Kuopio, Finland

6 Office of the Ombudsman for Children in Finland, Jyväskylä, Finland

7 Finnish Institute for Health and Welfare (THL), Oulu, Finland

8 Itla Children's Foundation, Helsinki, Finland

9 Department of Child Psychiatry, Turku University Hospital, Turku, Finland 
as well as of pathways from one service to another. This knowledge is instrumental for assessing the appropriate type, quantity, and timing of the psychiatric interventions required in child and family health and social services.

In a recent meta-analysis, the prevalence of current psychiatric disorder was $49 \%$ among children in OHC [2]. According to our literature review (see Supplement text and Supplement table 1), placement in OHC has been associated with several types of childhood psychiatric disorders, including depression and anxiety $[2,4,5,7$, 9, 13-16], oppositional defiant disorder/conduct disorder (ODD/CD) [2, 2, 4, 4, 5, 14-16, 9], post-traumatic stress disorder [2, 10], substance use disorders $[4,10,13,14,20$, $21]$, eating disorders $[13,14]$, and suicidal behavior [14, 22]. Placement in OHC has also been associated with neurodevelopmental disorders, such as attention-deficit/hyperactivity disorder (ADHD) [2, 4, 5, 7, 9, 14-16, 19] and learning disorders $[4,7,16]$. One Danish study has compared specialized psychiatric service use longitudinally, up to age 11 , between children in $\mathrm{OHC}$ and children never in OHC. Of the children in OHC, $20 \%$ had a psychiatric diagnosis compared with $3 \%$ among children never placed in OHC [5]. Existing evidence on service use due to psychiatric disorders is, however, mostly based on cross-sectional studies, small samples, or local service programmes, often without a comparison group. In addition, while the abovementioned studies have focused on psychiatric outcomes among children in $\mathrm{OHC}$, reports on placements into $\mathrm{OHC}$ among children treated for psychiatric disorders are rare $[8,23]$; such information is instrumental for assessing the need for social work within psychiatric clinics and vice versa. We are also not aware of any studies that investigate the temporal relation between entries into $\mathrm{OHC}$ and psychiatric services, which is important for understanding what kind of expertise is needed in both social and health services, as well as for identifying service pathways and the timing of the service use. In summary, evidence concerning the association between the need for psychiatric care and support by child welfare is insufficient.

To address these gaps in the evidence, we provide a comprehensive overview of psychiatric health service use and child welfare's OHC placements up to the age of 18 among a complete Finnish national birth cohort born in 1997. To examine the use of these two services bi-directionally, we first assessed the likelihood of specialized health service use among children placed in $\mathrm{OHC}$ in comparison with those never placed in OHC. In doing so, we investigated a range of diagnosed psychiatric and neurodevelopmental disorders and their comorbidity. Second, we assessed the likelihood of individuals with these diagnoses being placed in OHC. Based on previous findings, we expected that a range of diagnoses would be associated with OHC. Additionally, we examined the timing of first placement in $\mathrm{OHC}$ in relation to the first diagnosis of the investigated psychiatric and neurodevelopmental disorders.

\section{Methods}

\section{The study design and study population}

We used data from the 1997 Finnish Birth Cohort study. Managed by the Finnish Institute for Health and Welfare (THL), the birth cohort contains data from several nationwide registers for all children born in Finland during that year. We excluded individuals who emigrated or died before turning 18 . We followed all the included cohort members through registers from birth to their 18th birthday (i.e. 1997-2015) for entries into OHC and investigated psychiatric and neurodevelopmental disorder diagnoses up to that date. We followed the reporting recommendations of the Strengthening the Reporting of Observational Studies in Epidemiology (STROBE) guidelines for cohort studies (Supplement table 2).

\section{Data sources}

The personal identity codes assigned to all Finnish residents enable the accurate linkage of data from different registers into a single dataset. We used data provided by the Medical Birth Register [24] for the identification of the children born in Finland in 1997, their date of birth, and sex. In addition, we gathered data from the Child Welfare Register for placements in $\mathrm{OHC}$ and from the Care Register for Health Care [25] for the dates of inpatient and outpatient visits to public specialized hospital clinics and their accompanying diagnoses. Statistics Finland [24] provided data for dates and causes of death [26] and the Digital and Population Data Services Agency [24] provided data on emigration and residential location.

Maintained by the THL, the Child Welfare Register involves records of all children placed in OHC in Finland. The records include information on the start and end dates of placements, placement settings (e.g. foster care and residential care), and the legal grounds of the placement decision. The register is gathered by mandated biannual reporting from the municipal child welfare authorities from 1991 onwards, thus covering our follow-up from 1997 to 2015. In the Finnish child welfare system, $\mathrm{OHC}$ is considered a last-resort measure, which is taken after in-home services have proven inappropriate, insufficient, or impossible. Municipal child welfare authorities make the decision to place a child in $\mathrm{OHC}$ if the parents and children agree with 
the measures and in emergency situations. Contested care orders are decided in an administrative court.

Data on visits to specialized health services are based on the Care Register for Health Care, maintained by the THL. The register includes records of the start and end dates of visits to any hospital inpatient unit or outpatient clinic in public hospitals, a mandatory primary diagnosis, and optional secondary diagnoses. Inpatient data are available from 1969 and outpatient data from 1998, meaning that the outpatient records are partly incomplete for the first year of the 1997 birth cohort. The register has been widely used in epidemiological research [25], including studies on the diagnostic validity of several disorders [27-29] and a study on the incidence of specialized psychiatric health care use in adolescents in the 1997 birth cohort [30].

\section{Measures}

We defined experience of $\mathrm{OHC}$ as any placement in $\mathrm{OHC}$ before a person's 18 th birthday. This measure thus captures children in OHC for both the short and long term, including those who reunited with their families during the study period. We studied lifetime prevalence rates of psychiatric diagnoses, which we defined as an inpatient and outpatient specialized health service visit before the person's $18^{\text {th }}$ birthday. For measurement, we investigated primary and secondary diagnoses according to the 10th revision of the International Classification of Diseases (ICD-10) for any psychiatric disorder (ICD-10 codes F10-F99) and separately according to the seven diagnostic classes specified in the Supplementary appendix (Supplement table 3); consequently, each person could be recorded under one or more of these specific diagnostic classes. In addition, to investigate the temporal relation between first placement and first diagnosis, we used age at first placement and age at first diagnosis as continuous variables.

\section{Statistical analysis}

We examined cumulative probabilities (i.e. from birth to the age of 18) for visits to psychiatric outpatient clinics and inpatient care among children with experience of $\mathrm{OHC}$, as well as cumulative probabilities for placement in $\mathrm{OHC}$ among children diagnosed with specified psychiatric and neurodevelopmental disorders by the age of 18 . To quantify the association between placement in OHC and psychiatric service use, and vice versa, we computed crude risk ratios $(R R \mathrm{~s})$ with $95 \%$ confidence intervals (CIs). The RR was computed by dividing the cumulative probability in the exposed group by the cumulative probability in the unexposed group. We investigated the timing between the first placement and the first diagnosis using descriptive methods. We also completed several additional and sensitivity analyses (see Supplementary appendix). We conducted the analyses with R for Windows (version 3.6) [31].

\section{Results}

There were 58,802 individuals in the Finnish Birth Cohort 1997 study who survived the perinatal period. After excluding those who had any history of emigration $(n=1370)$ or died $(n=258)$ before the end of the follow-up at the age of 18 , the population comprised 57,174 individuals.

Of the study population, 3254 (5.7\%) individuals experienced placement in $\mathrm{OHC}$ before the age of 18 . The median (interquartile range) age at first placement was 12.7 years (5.58-15.1 years) (Table 1), with first placements peaking at infancy (age 0) and in adolescence (ages 14-15). The most typical placement settings were residential care $(61.9 \%$ of those placed in OHC) and a foster family (19.5\%) (Table 1), with foster families dominating among those placed in care for the long term at younger ages and residential care dominating among those placed for the short term and during adolescence (not shown in the table).

We observed 11,821 (20.7\% of the cohort) individuals who used outpatient or inpatient specialized services for any psychiatric or neurodevelopmental disorder before age 18 (Fig. 1). Of these children, 2139 (18.1\%) had been placed in OHC, compared with 1115 (2.5\%) of the 45353 individuals with no diagnosis (RR of OHC: 7.4; 95\% CI 6.9-7.9). Of those with experience of $\mathrm{OHC}, 61.9 \%$ had any diagnosis, compared with $18.0 \%$ among those never in $\mathrm{OHC}$ (RR of

Table 1 Children in out-of-home care in the 1997 birth cohort by placement characteristics

\begin{tabular}{ll}
\hline & $\begin{array}{l}\text { All children in } \\
\text { out-of-home } \\
\text { care }\end{array}$ \\
\hline Sex, no. (\%) & $1608(49.4)$ \\
Boys & $1646(50.6)$ \\
Girls & $12.7(5.6-15.1)$ \\
Age at first placement, median (IQR) & $396(62-1417)$ \\
Total length of time in care, days, median (IQR) & $3(1-5)$ \\
Number of placements, median (IQR) & \\
Most typical placement setting, no. (\%) & $634(19.5)$ \\
Foster family & $472(14.5)$ \\
Professional foster home & $2014(61.9)$ \\
Residential care & $134(4.1)$ \\
Other settings & 3254 \\
Total, no. &
\end{tabular}

$I Q R$ inter quartile range 


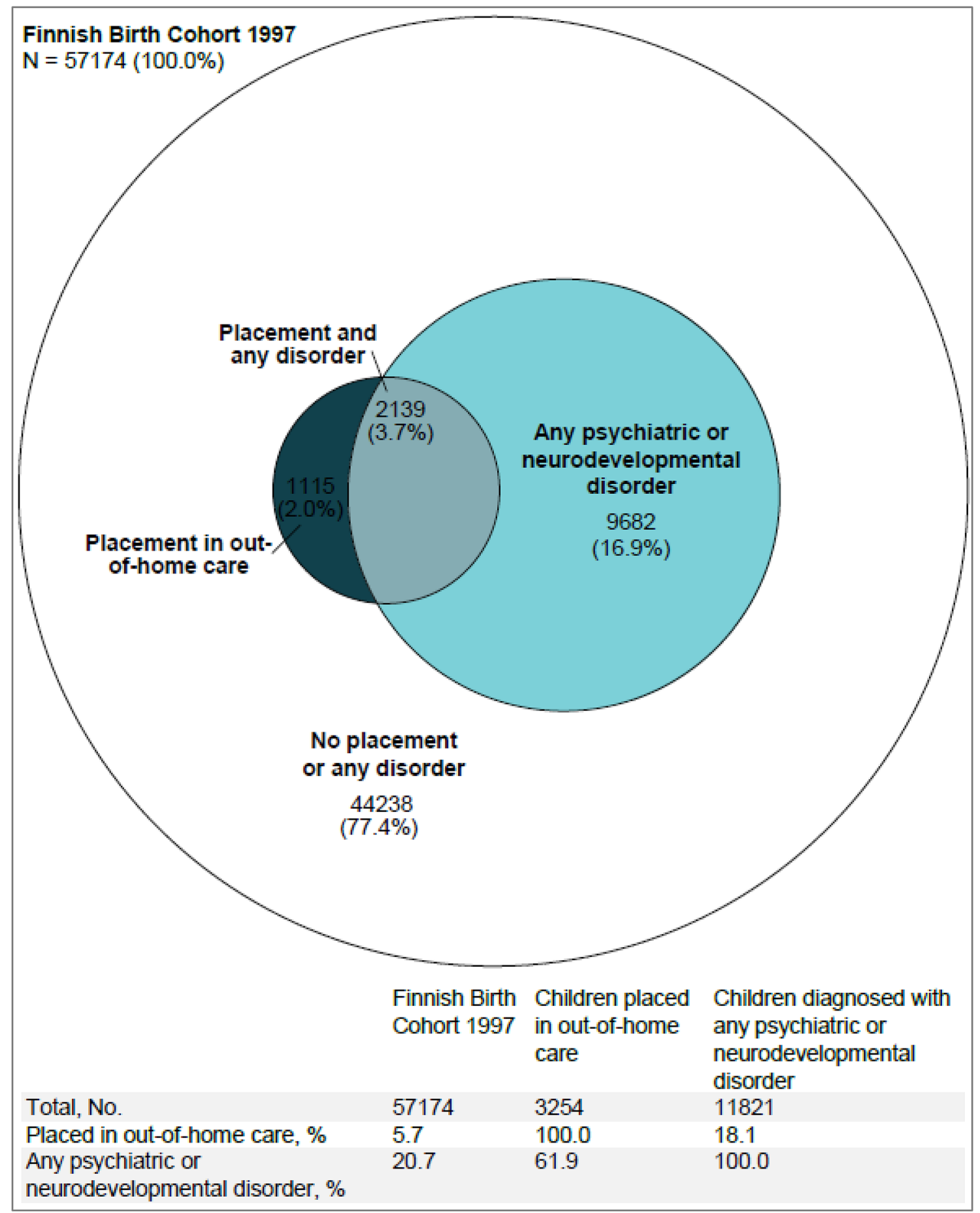

Fig. 1 A Euler diagram of individuals in the Finnish Birth Cohort 1997 placed in out-of-home care and diagnosed with any psychiatric or neurodevelopmental disorder

diagnosis: 3.7; 95\% CI 3.6-3.8). Restricting the analysis to inpatient records alone suggests that children in $\mathrm{OHC}$ are even more disproportionally present in inpatient units than in outpatient clinics (Supplement text and Supplement Figs. 1 and 2). Sex-stratified analysis indicates that psychiatric service use due to any psychiatric or neurodevelopmental disorder concerns both sexes similarly (Supplement text and Supplement Figs. 3 and 4).

Children with experience of OHC were much more likely to use specialized services due to each of the specific disorders compared with those never placed in OHC (see Fig. 2). The most common diagnosed disorders among children in 


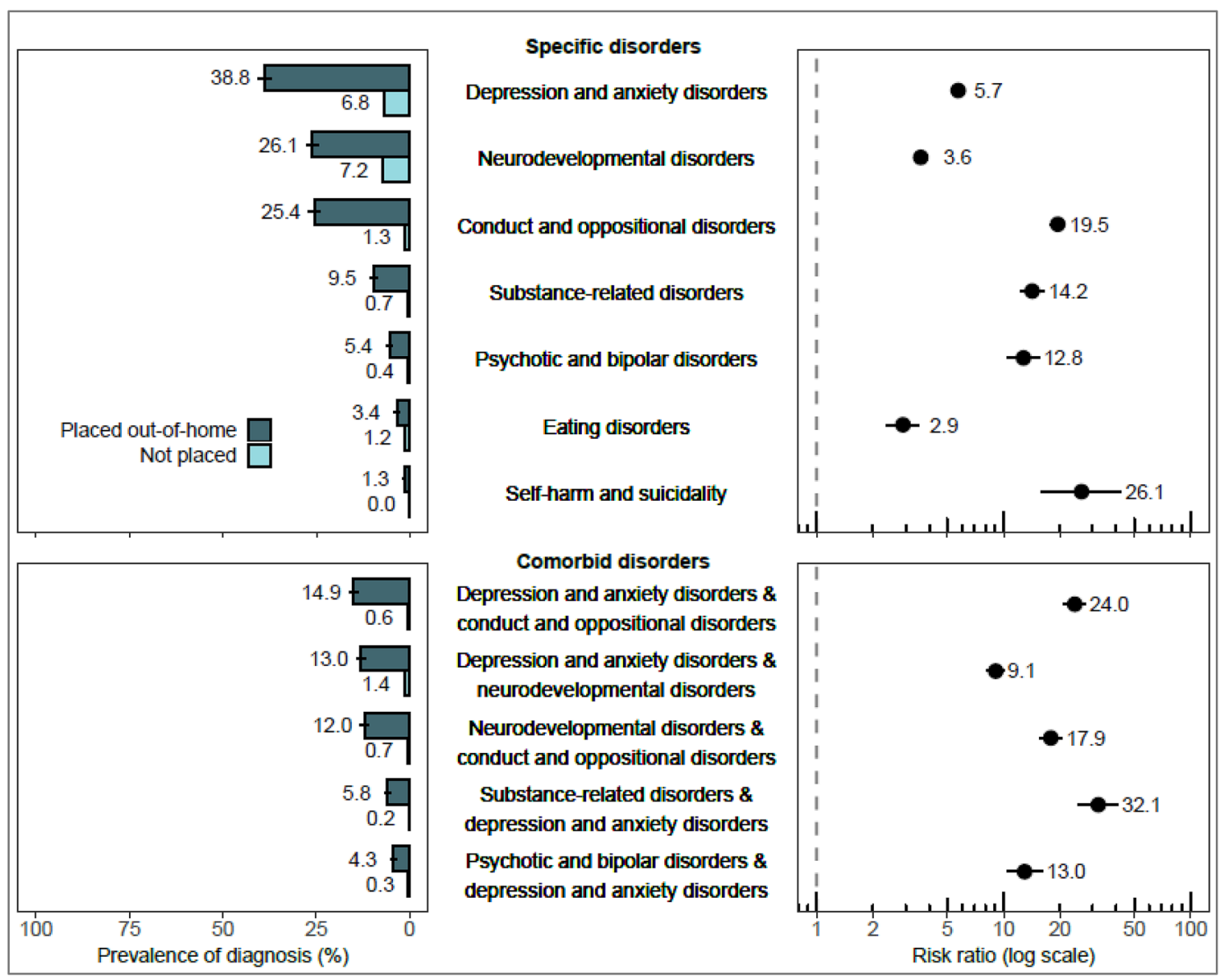

Fig. 2 The risks of specific psychiatric or neurodevelopmental disorder diagnoses and the five most common comorbid diagnostic classes among children in out-of-home care compared with children never in out-of-home care

OHC were depression and anxiety disorders (38.8\% vs. $6.8 \%$ among those never placed), neurodevelopmental disorders (26.1\% vs. $7.2 \%$ ), and ODD/CD (25.4\% vs. $1.3 \%$ ) (Fig. 2). Children with experience of $\mathrm{OHC}$ were also frequently diagnosed with comorbid combinations of these three most common diagnostic classes, with cumulative probabilities ranging from 12.0 to $14.9 \%$ (Fig. 2). Children in $\mathrm{OHC}$ had the highest RRs for self-harm and suicidality (RR: 26.1; 95\% CI 16.0-42.7) and ODD/CD (RR: 19.5; 95\% CI 17.7-21.4) (Fig. 2). Their RRs were also high or very high for most comorbid combinations.

Those diagnosed with some of the specific disorders had high probabilities of having experience of OHC. More than half of the individuals diagnosed with self-harm and suicidality $(61.2 \%)$ and ODD/CD (54.1\%) experienced placement in $\mathrm{OHC}$ (Fig. 3). In addition, large percentages of children diagnosed with substance-related disorders $(46.2 \%)$ and psychotic and bipolar disorders (43.5\%) had experience of OHC. The likelihood of placement was further increased among those with comorbid diagnoses. Most notably, of those with ODD/CD and a comorbid self-harm and suicidality diagnosis, $95.8 \%$ had been in OHC.

Age at first placement in $\mathrm{OHC}$ and age at first diagnosis of any psychiatric or neurodevelopmental disorder correlated moderately $(R=0.32)$ and occurred, on average, at the same time (mean time difference between first placement and first diagnosis: -0.02 years; $95 \% \mathrm{CI}-0.27$ to 0.23 ), with both events occurring in adolescence (Fig. 4). Approximately, half of the children who had both experience of $\mathrm{OHC}$ and a diagnosis of any disorder were diagnosed before the first placement. However, we observed differences in timing when examining specific disorders. ODD/CD diagnoses seemed to co-occur most closely with first placements in OHC $(R=0.37)$. In addition, substance-related disorders, and self-harm and suicidality were diagnosed after the first placement in three out of four cases.

Our results from the sensitivity analyses were similar to the main analysis (see Supplement text and Supplement Figs. 5-8). 


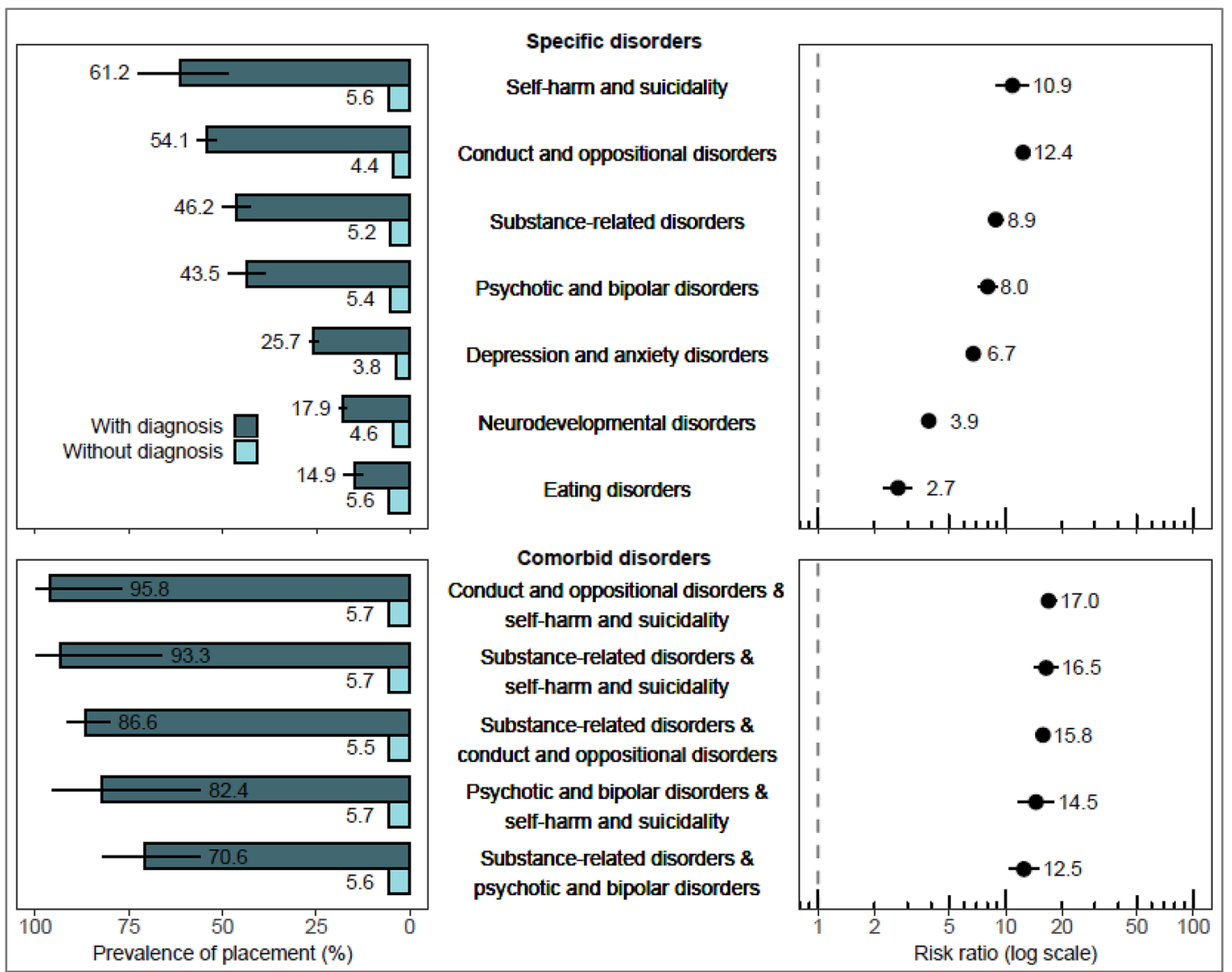

Fig. 3 The risk of placement in out-of-home care among children with specific psychiatric or neurodevelopmental disorder diagnoses compared with children without such diagnoses, including five comorbid diagnostic classes with the highest proportion of placements

\section{Discussion}

The strengths of the present study are the total population coverage of children born in 1997 in Finland and the reliable nationwide register-based follow-up until age 18 . The main results are, first, that the majority of children with experience in $\mathrm{OHC}$ were diagnosed with a psychiatric or neurodevelopmental disorder in specialized services during childhood. In addition, approximately one in five children with a diagnosed disorder experienced placement in $\mathrm{OHC}$, compared with approximately 1 in 40 children without such a diagnosis. Most notably, the majority among those diagnosed with self-harm and ODD/CD experienced placement in $\mathrm{OHC}$.

Our findings indicate that most children placed in $\mathrm{OHC}$ are treated for psychiatric or neurodevelopmental disorders, confirming previous evidence [2-16]. Accordingly, we noted significant differences in the likelihood of childhood and adolescence psychiatric service use between children who experienced placement in OHC and those who did not. Our findings are in line with previous research in showing that children with experience of $\mathrm{OHC}$ are frequently treated for depression and anxiety disorders, neurodevelopmental disorders, and ODD/CD [2, 4, 5, 7, 9, 10, 13-16, 19]. In addition, the prevalence of substance-related disorders in this study is approximately the same as that found by a review on the prevalence of lifetime alcohol and drug abuse among children in $\mathrm{OHC}$ [20]. The prevalence of self-harm and suicidality among children in $\mathrm{OHC}$ in this study was $1.3 \%$, which is low compared with the prevalence of suicide attempts in a meta-analysis (3.6\%) [22]. This difference may result from different ascertainment methods since the metaanalysis included self-reports while we used only inpatient and outpatient records.

This study add to the scarce literature on the experience of $\mathrm{OHC}$ among those receiving psychiatric services [8, 23]. Halfon et al. [8] used utilization data from California's Medi-Cal programme from the 1980s, and Kiuru and Metteri [23] relied on data from one Finnish psychiatric hospital, whereas our study covers one full national birth cohort. We found that children in OHC comprised $18.1 \%$ of all children who received inpatient and outpatient services due to 


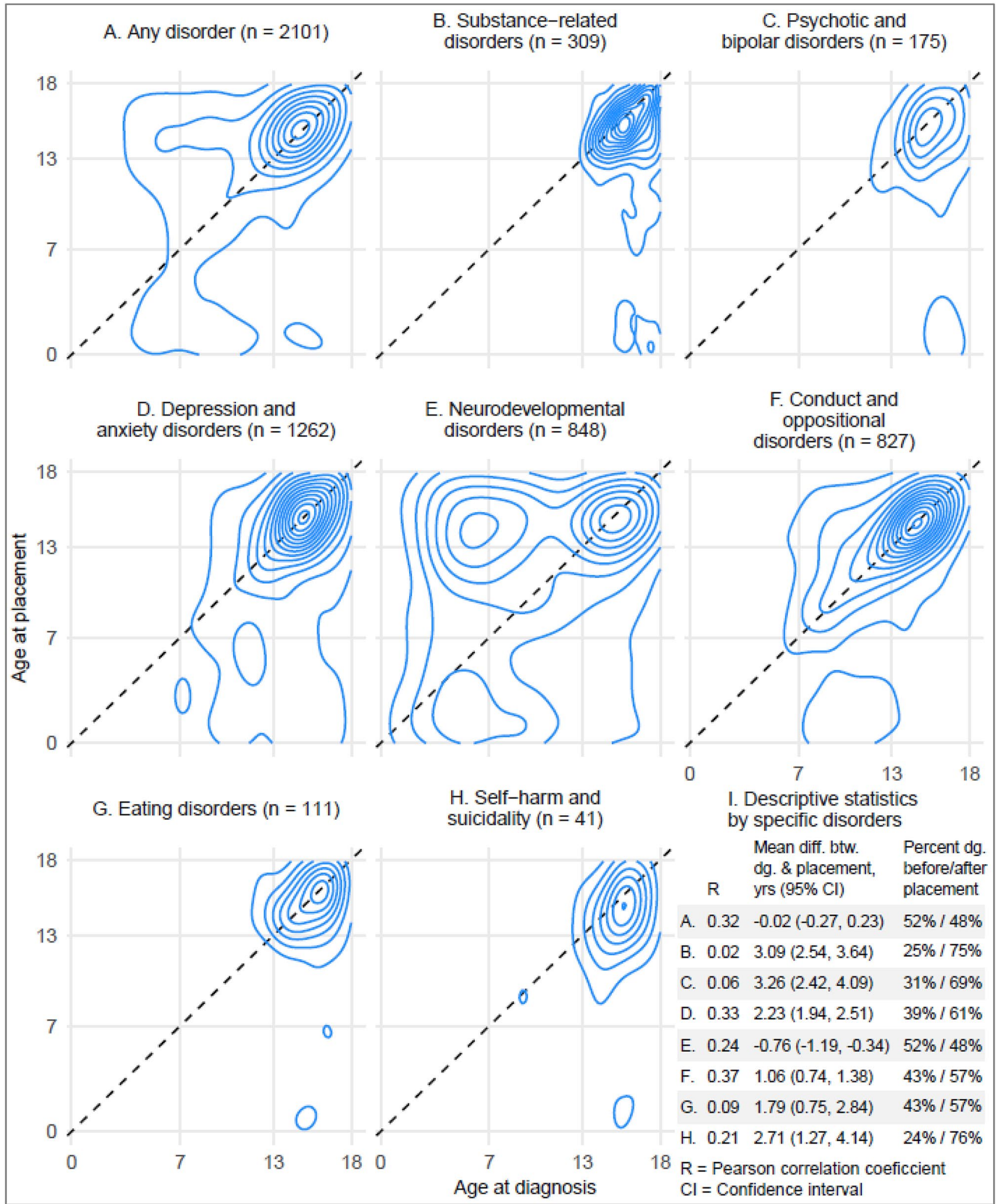

Fig. 4 The timing of first placement into out-of-home care versus the timing of first diagnoses among those with experience of out-of-home care and diagnosed psychiatric or neurodevelopmental disorders 
psychiatric and neurodevelopmental disorders, although they represented just $5.7 \%$ of the cohort. Halfon et al. [8] found that foster children were even more disproportionately present in psychiatric services, which could be explained by contextual differences between California and Finland. We noted that children with experience of OHC comprised very high proportions of those diagnosed with self-harm and suicidality, ODD/CD, substance-related disorders, psychotic and bipolar disorders, and various comorbid combinations of the investigated disorders.

There are several potential explanations for the overrepresentation of children with experience of $\mathrm{OHC}$ in psychiatric services. First, due to several reasons-such as a history of maltreatment, trauma, and genetic vulnerability-psychiatric disorders are more common among children in $\mathrm{OHC}$ than in the general population that is not in $\mathrm{OHC}$, even before entering OHC [15]. Furthermore, a meta-analysis indicates that being in $\mathrm{OHC}$ has no effect on these children's internalizing, externalizing, or total behavior problems [32], suggesting that elevated psychiatric needs among these children persist even while being placed in $\mathrm{OHC}$. Second, evidence indicates that being in $\mathrm{OHC}$ facilitates access to psychiatric services [3, 6], which may result, for example, from the improved identification of needs or referrals by social services. Our findings also highlight the possibility that, vice versa, receiving psychiatric care may increase the likelihood of entering OHC. Third, OHC is targeted not only at maltreated and disadvantaged children, but also to children and young people whose behavior, such as criminality and substance use, puts them at risk. This is then directly related to some disorders, including ODD/CD and substance-related disorders, via diagnostic criteria if these individuals are referred to psychiatric services.

We also observed that age at first entry into OHC and age at first diagnosis of any psychiatric or neurodevelopmental disorder co-occurred to a moderate extent and occurred, on average, at the same age in adolescence. Increased psychiatric needs and service use during adolescence among children in $\mathrm{OHC}$ has also been noted by other studies $[3,7,8,15]$. The accumulation of first diagnoses and placements in adolescence may result from earlier, possibly subthreshold or undiagnosed psychiatric problems as these strongly predict later adverse outcomes, including psychopathology and antisocial behaviors [33-35], which may instigate child's placement into OHC. In addition, we noted some disorder-specific variance in the correlation between age at first diagnosis and age at first entry into OHC. Specifically, placement and diagnosis ages were most strongly correlated for ODD/CD, most likely indicating that placing a child in $\mathrm{OHC}$ is a typical response to severe behavioral disorders. However, the timing of service entries may inform us of service provision, even if the correlation between diagnosis and placement age is weak or non-existent. When we observed children who were both placed in $\mathrm{OHC}$ and treated in psychiatric services, we noted that approximately half of them were diagnosed before their first entry into OHC. On the one hand, this suggests that psychiatric and neurodevelopmental disorders are often already treated before entering OHC. For example, neurodevelopmental disorders are typically diagnosed before school age or at elementary school age, while a large proportion of placements in $\mathrm{OHC}$ among children with these types of disorders occur during adolescence. On the other hand, some disorders were mostly diagnosed after first entry into OHC. These included selfharm and suicidality, substance-related disorders, and psychotic and bipolar disorders, for which adolescence is the typical period of onset.

Our findings underscore, first, the necessity of mental health assessment among children who are referred to OHC. Specific attention should be given to self-harming behavior, and severe and complex behavioral and emotional disorders for those who enter $\mathrm{OHC}$ at school age and adolescence. In addition, to treat mental health among children who are placed in $\mathrm{OHC}$, the $\mathrm{OHC}$ system requires adequate resources in terms of knowledge, skills, and capacity. This includes social workers and children's carers who work with these children in foster families and institutional settings on a daily basis understanding mental and behavioral health. Children in OHC with specific disorders may also benefit from evidence-based interventions, including multidimensional treatment foster care targeted at children with behavioral disorders [36]. Given that half of children in $\mathrm{OHC}$ with diagnosed psychiatric and neurodevelopmental disorders in this study were diagnosed before entering OHC, preventive interventions form an important approach. Several elements of effective youth- and family-directed interventions have been identified [37], but the development of effective family support interventions for families at risk of a child's OHC placement remains a challenge [38]. In Finland, there is promising evidence from a parent training intervention offered for parents of preschool children with disruptive behavioral problems [39]. However, the implementation of evidence-based interventions for young people is lacking in the country, particularly in primary care settings.

Strengths of our study include the large nationwide register data that enables us to investigate rare disorders and to follow-up a complete birth cohort throughout the entire childhood without selection or attrition biases. In addition, our sensitivity analyses suggest that the findings are robust to some potential sources of bias (see Supplementary appendix). Limitations include, first, that our study is based on real-world clinical diagnoses given in specialized health care, meaning that we have to rely on the categorical diagnoses recorded in the data and have no data on children who are only treated in primary care. This means that service use 
due to less severe disorders is more likely to be excluded. Therefore, our findings should be interpreted primarily in the context of specialized health care. Second, because child welfare and health care systems vary across countries, generalizations outside Finland should be made with caution. However, our findings seem to reflect international evidence, thus similar patterns are likely to be found elsewhere.

\section{Conclusion}

The majority of children with experience in $\mathrm{OHC}$ require mental health treatment, and they comprise a notable proportion of those who are treated for serious and complex psychiatric disorders and self-harm. This necessitates understanding the mental health issues in child welfare services and the social issues in psychiatric services, low-threshold collaboration between child welfare and psychiatric services, appropriately trained staff, and the timely and flexible provision of psychiatric support for children in OHC. Considering that psychiatric and neurodevelopmental disorders are associated with a wide range of immediate and long-term negative outcomes, and that the provision of $\mathrm{OHC}$ and psychiatric services is very expensive, developing effective early prevention strategies is essential, specifically for children who exhibit known risks of becoming placed in $\mathrm{OHC}$ as adolescents.

Supplementary Information The online version contains supplementary material available at https://doi.org/10.1007/s00787-021-01819-1.

Acknowledgements The study was supported by the Academy of Finland and is part of the INVEST Research Flagship (\#320162) and PSYCOHORTS consortia (\#308552). DG has received funding from the Academy of Finland (\#297598), a NARSAD Young Investigator grant from the Brain and Behavior Research Foundation and the Finnish Medical Foundation. We thank Pia Pörtfors (THL) for her assistance with the literature search.

Funding Open access funding provided by National Institute for Health and Welfare (THL).

Availability of data and materials Access to research data is subject to research permits from the Finnish Institute for Health and Welfare and respective register holders, as mandated by Finnish data protection laws and policies of the register holders.

\section{Declarations}

Conflict of interest The authors declare no conflict of interest.

Ethical approval The study obtained ethical approval of the Ethical committee at the Finnish Institute for Health and Welfare \$572/2013 and have therefore been performed in accordance with the ethical standards laid down in the 1964 Declaration of Helsinki and its later amendments. The dataset of this study was managed as mandated by
Finnish data protection legislation. According to Finnish law, registerbased studies do not require informed consent.

Consent for publication All of the authors approved the manuscript's submission for publication.

Open Access This article is licensed under a Creative Commons Attribution 4.0 International License, which permits use, sharing, adaptation, distribution and reproduction in any medium or format, as long as you give appropriate credit to the original author(s) and the source, provide a link to the Creative Commons licence, and indicate if changes were made. The images or other third party material in this article are included in the article's Creative Commons licence, unless indicated otherwise in a credit line to the material. If material is not included in the article's Creative Commons licence and your intended use is not permitted by statutory regulation or exceeds the permitted use, you will need to obtain permission directly from the copyright holder. To view a copy of this licence, visit http://creativecommons.org/licenses/by/4.0/.

\section{References}

1. Petrowski N, Cappa C, Gross P (2017) Estimating the number of children in formal alternative care: challenges and results. Child Abuse Negl 70:388-398. https://doi.org/10.1016/j.chiabu.2016. 11.026

2. Bronsard G, Alessandrini M, Fond G, Loundou A, Auquier P, Tordjman S, Boyer L (2016) The prevalence of mental disorders among children and adolescents in the child welfare system: a systematic review and meta-analysis. Medicine 95:e2622. https:// doi.org/10.1097/MD.0000000000002622

3. Burns BJ, Phillips SD, Wagner HR, Barth RP, Kolko DJ, Campbell Y, Landsverk J (2004) Mental health need and access to mental health services by youths involved with child welfare: a national survey. J Am Acad Child Adolesc Psychiatry 43:960970. https://doi.org/10.1097/01.chi.0000127590.95585.65

4. dosReis S, Zito JM, Safer DJ, Soeken KL (2001) Mental health services for youths in foster care and disabled youths. Am J Public Health 91:1094-1099. https://doi.org/10.2105/ajph.91.7.1094

5. Egelund T, Lausten M (2009) Prevalence of mental health problems among children placed in out-of-home care in Denmark. Child Fam Soc Work 14:156-165. https://doi.org/10.1111/j.13652206.2009.00620.x

6. Farmer EMZ, Chapman MV, Phillips SD, Angold A, Jane Costello E, Burns BJ (2001) Use of mental health services by youth in contact with social services. Soc Serv Rev 75:605-624. https:// doi.org/10.1086/323165

7. Ford T, Vostanis P, Meltzer H, Goodman R (2007) Psychiatric disorder among British children looked after by local authorities: comparison with children living in private households. Br J Psychiatry 190:319-325. https://doi.org/10.1192/bjp.bp.106.025023

8. Halfon N, Berkowitz G, Klee L (1992) Mental health service utilization by children in foster care in California. Pediatrics 89:1238-1244

9. Harman JS, Childs GE, Kelleher KJ (2000) Mental health care utilization and expenditures by children in foster care. Arch Pediatr Adolesc Med 154:1114-1117. https://doi.org/10.1001/archpedi. 154.11.1114

10. Havlicek JR, Garcia AR, Smith DC (2013) Mental health and substance use disorders among foster youth transitioning to adulthood: past research and future directions. Child Youth Serv Rev 35:194-203. https://doi.org/10.1016/j.childyouth.2012.10.003 
11. Keyser D, Ahn H (2017) predictors of mental health and developmental service utilization among children age birth to 5 years in child welfare: a systematic review. J Public Child Welf 11:388412. https://doi.org/10.1080/15548732.2017.1339656

12. Oswald SH, Heil K, Goldbeck L (2010) history of maltreatment and mental health problems in foster children: a review of the literature. J Pediatr Psychol 35:462-472. https://doi.org/10.1093/ jpepsy/jsp114

13. Pecora PJ, White CR, Jackson LJ, Wiggins T (2009) Mental health of current and former recipients of foster care: a review of recent studies in the USA. Child Fam Soc Work 14:132-146. https://doi. org/10.1111/j.1365-2206.2009.00618.x

14. Pilowsky DJ, Wu L (2006) Psychiatric symptoms and substance use disorders in a nationally representative sample of American adolescents involved with foster care. J Adolesc Health 38:351358. https://doi.org/10.1016/j.jadohealth.2005.06.014

15. Steele JS, Buchi KF (2008) Medical and mental health of children entering the Utah foster care system. Pediatrics 122:e703-e709. https://doi.org/10.1542/peds.2008-0360

16. Turney K, Wildeman C (2016) Mental and physical health of children in foster care. Pediatrics 138:e20161118. https://doi.org/10. 1542/peds.2016-1118

17. De Swart JJW, Van den Broek H, Stams GJJM, Asscher JJ, Van der Laan PH, Holsbrink-Engels GA, Van der Helm GHP (2012) The effectiveness of institutional youth care over the past three decades: a meta-analysis. Child Youth Serv Rev 34:1818-1824. https://doi.org/10.1016/j.childyouth.2012.05.015

18. Whittaker JK, Holmes L, del Valle JF, Ainsworth F, Andreassen T, Anglin J, Bellonci C, Berridge D, Bravo A, Canali C, Courtney M, Currey L, Daly D, Gilligan R, Grietens H, Harder A, Holden M, James S, Kendrick A, Knorth E, Lausten M, Lyons J, Martin E, McDermid S, McNamara P, Palareti L, Ramsey S, Sisson K, Small R, Thoburn J, Thompson R, Zeira A (2016) Therapeutic residential care for children and youth: a consensus statement of the international work group on therapeutic residential care. Resid Treat Child Youth 33:89-106. https://doi.org/10.1080/0886571X. 2016.1215755

19. Willis R, Dhakras S, Cortese S (2017) Attention-deficit/hyperactivity disorder in looked-after children: a systematic review of the literature. Curr Dev Disord Rep 4:78-84. https://doi.org/10.1007/ s40474-017-0116-z

20. Braciszewski JM, Stout RL (2012) Substance use among current and former foster youth: a systematic review. Child Youth Serv Rev 34:2337-2344. https://doi.org/10.1016/j.childyouth.2012.08. 011

21. Siegel A, Benbenishty R, Astor RA (2016) A comparison of adolescents in foster care and their peers in high school: a study of substance use behaviors and attitudes. J Child Adolesc Subst Abuse 25:530-538. https://doi.org/10.1080/1067828X.2016. 1139481

22. Evans R, White J, Turley R, Slater T, Morgan H, Strange H, Scourfield J (2017) Comparison of suicidal ideation, suicide attempt and suicide in children and young people in care and non-care populations: systematic review and meta-analysis of prevalence. Child Youth Serv Rev 82:122-129. https://doi.org/10.1016/j.childyouth. 2017.09.020

23. Kiuru K, Metteri A (2014) Lastensuojelun ja nuorisopsykiatrian yhteisasiakkuus potilaskertomusaineistossa. Sos Laaketiet Aikak 51:146-160

24. Gissler M, Haukka J (2004) Finnish health and social welfare registers in epidemiological research. Nor Epidemiol 14:113-120. https://doi.org/10.5324/nje.v14i1.284

25. Sund R (2012) Quality of the Finnish hospital discharge register: a systematic review. Scand J Public Health 40:505-515. https:// doi.org/10.1177/1403494812456637

26. Lahti RA, Penttilä A (2003) Cause-of-death query in validation of death certification by expert panel; effects on mortality statistics in Finland, 1995. Forensic Sci Int 131:113-124. https://doi.org/ 10.1016/S0379-0738(02)00418-8

27. Kieseppä T, Partonen T, Kaprio J, Lönnqvist J (2000) Accuracy of register- and record-based bipolar I disorder diagnoses in Finland; a study of twins. Acta Neuropsychiatr 12:106-109. https://doi.org/ $10.1017 /$ S0924270800035535

28. Lampi KM, Sourander A, Gissler M, Niemelä S, Rehnström K, Pulkkinen E, Peltonen L, Von Wendt L (2010) Brief report: validity of Finnish registry-based diagnoses of autism with the ADI-R. Acta Paediatr 99:1425-1428. https://doi.org/10.1111/j.1651-2227. 2010.01835.x

29. Joelsson P, Chudal R, Gyllenberg D, Kesti A, Hinkka-YliSalomäki S, Virtanen J, Huttunen J, Ristkari T, Parkkola K, Gissler M, Sourander A (2015) Demographic characteristics and psychiatric comorbidity of children and adolescents diagnosed with ADHD in specialized healthcare. Child Psychiatry Hum Dev 47:574-582. https://doi.org/10.1007/s10578-015-0591-6

30. Gyllenberg D, Marttila M, Sund R, Jokiranta-Olkoniemi E, Sourander A, Gissler M, Ristikari T (2018) Temporal changes in the incidence of treated psychiatric and neurodevelopmental disorders during adolescence: an analysis of two national Finnish birth cohorts. Lancet Psychiatry 5:227-236. https://doi.org/10. 1016/S2215-0366(18)30038-5

31. R Core Team (2019) R: a language and environment for statistical computing. R Foundation for Statistical Computing, Vienna, Austria

32. Goemans A, van Geel M, Vedder P (2015) Over three decades of longitudinal research on the development of foster children: a meta-analysis. Child Abuse Negl 42:121-134. https://doi.org/10. 1016/j.chiabu.2015.02.003

33. Copeland WE, Shanahan L, Costello EJ, Angold A (2009) Childhood and adolescent psychiatric disorders as predictors of young adult disorders. Arch Gen Psychiatry 66:764-772. https://doi.org/ 10.1001/archgenpsychiatry.2009.85

34. Copeland WE, Wolke D, Shanahan L, Costello EJ (2015) Adult functional outcomes of common childhood psychiatric problems: a prospective, longitudinal study. JAMA Psychiatry 72:892-899. https://doi.org/10.1001/jamapsychiatry.2015.0730

35. Sourander A, Elonheimo H, Niemelä S, Nuutila A, Helenius H, Sillanmäki L, Piha J, Tamminen T, Kumpulainen K, Moilanen I, Almqvist F (2006) Childhood predictors of male criminality: a prospective population-based follow-up study from age 8 to late adolescence. J Am Acad Child Adolesc Psychiatry 45:578-586. https://doi.org/10.1097/01.chi0000205699.58626.b5

36. Lee T, Fouras G, Brown R (2015) Practice parameter for the assessment and management of youth involved with the child welfare system. J Am Acad Child Adolesc Psychiatry 54:502-517. https://doi.org/10.1016/j.jaac.2015.03.005

37. Lee BR, Ebesutani C, Kolivoski KM, Becker KD, Lindsey MA, Brandt NE, Cammack N, Strieder FH, Chorpita BF, Barth RP (2014) Program and practice elements for placement prevention: a review of interventions and their effectiveness in promoting homebased care. Am J Orthopsychiatry 84:244-256. https://doi.org/10. 1037/h0099811

38. Al CM, Stams GJJ, Bek MS, Damen EM, Asscher JJ, van der Laan PH (2012) A meta-analysis of intensive family preservation programs: placement prevention and improvement of family functioning. Child Youth Serv Rev 34:1472-1479

39. Sourander A, McGrath PJ, Ristkari T, Cunningham C, Huttunen J, Lingley-Pottie P, Hinkka-Yli-Salomäki S, Kinnunen M, Vuorio J, Sinokki A, Fossum S, Unruh A (2016) Internet-assisted parent training intervention for disruptive behavior in 4-year-old children: a randomized clinical trial. JAMA Psychiatry 73:378-387. https://doi.org/10.1001/jamapsychiatry.2015.3411 